\title{
Dental Amalgam Influence on the Amount of Absorbed Energy from Mobile Phone
}

\author{
Nenad N. Cvetkovic ${ }^{1}$, Marko A. Dimitrijevic ${ }^{1,{ }^{*}}$, Dejan B. Jovanovic ${ }^{1}$, Dragana U. Zivaljevic ${ }^{1}$, \\ Dragan D. Krasic ${ }^{2}$ \\ ${ }^{I}$ Faculty of Electronic Engineering, University of Nis, \\ A. Medvedeva 14, 18000 Nis, Serbia \\ ${ }^{2}$ Faculty of Medicine, University of Nis, \\ Blvd. Dr Zorana Djindjica 81, 18000 Nis, Serbia \\ marko.dimitrijevic@elfak.ni.ac.rs
}

\begin{abstract}
The topic of the research presented in this paper is numerical calculation and analysis of the electric field and Specific Absorption Rate (SAR) distributions in the vicinity of dental amalgam exposed to the radiation of mobile phone at the frequencies corresponding to $3 \mathrm{G}$ and $4 \mathrm{G}$ mobile networks. This is carried out by numerical solving of the electromagnetic propagation equation. The results related to different tissues and organs placed in the vicinity of dental amalgam and exposed to radiation are presented and analysed. In order to obtain the most accurate results, the realistic 3D model of human jaw has been created. A comparative analysis of models with and without dental amalgam has been carried out, with aim to determine the impact of amalgam on biological tissues in its vicinity. According to the obtained results, the maximum values of electric field strength and SAR are higher in the presence of dental amalgam. In both cases, maximum values are out of bounds of safety limits.
\end{abstract}

Index Terms - Dental amalgam; Electromagnetic radiation; Mobile communication; Specific absorption rate.

\section{INTRODUCTION}

In the last few years, mobile phones and communication systems as well have been developing at an astounding rate. Due to numerous advantages and opportunities, one can observe the massive growth in the usage of mobile phones, including the time spent using them. This brings significantly increasing exposure to electromagnetic radiation caused by a cell phone, which turned the focus towards researching the impact of electromagnetic waves on human organism and estimation of human health risk. The cell phones, as nonionizing electromagnetic radiations sources placed in the vicinity of the human head, should be considered as the potential health hazards. There are many previously realized studies dealing with this problem. Based on them, the corresponding safety measures prescribing maximal allowable values for electromagnetic field exposure have been included in published safety standards and recommendations [1]-[4]. In addition, it is necessary to emphasize that electromagnetic field has been characterized

Manuscript received 3 April, 2020; accepted 5 July, 2020

This research was funded by Serbian Ministry of Education, Science and Technology Development under grants (No. TR32004, No. III44004, and No. III43012). as potentially carcinogenic risk for humans and classified as 2B carcinogen [5]. The initial researches of electric field and Specific Absorption Rate (SAR) distributions firstly included simple models containing only one layer that was supposed to represent the human brain characteristics Results obtained in such a way, for understandable reasons, do not reflect the real situation related to the certain tissues. In addition, because of their simplicity, these models could not consider the boundary conditions at the transitions between different biological tissues and organs [6]-[8]. Numerous studies refer to the cell phone radiation impact inside realistic 3D model of a human head containing different tissues and organs [9]-[13]. These 3D models are very good approximations of actual human head state, which provide accurate analysis of electric field and SAR distributions in biological tissues inside the head. However, the framework of these studies has not focused on the oral region of a head.

The main aim of this study is to determine the electric field distribution and values of SAR in the vicinity of dental amalgam exposed to the source of electromagnetic radiation. As a source of radiation, the actual smart phone has been modelled. It is a well-known fact that the dental amalgam (silver fillings) is a mixture of metals consisting of liquid mercury and a powdered alloy composed of silver, tin, and copper. The concentration of mercury in the dental amalgam varies depending on the manufacturer and can cause serious health problems.

Some of previous studies refer to the impact of electromagnetic field on dental amalgam. Many articles have been researching health problems and unpleasant symptoms caused by the electromagnetic waves emitted by wireless devices [14]-[26]. Some of them reported the involuntary movements of the subject that were treated using a gold alloy dental inlay caused by electromagnetic waves [17].

Due to the lack of numerical analysis of electric field distribution, as well as values of SAR in the vicinity of dental amalgam in available literature, researching in this field has been performed. Hence, the main aim of this paper is to evaluate and estimate of the mobile phone radiation exposure effects in the dental amalgam vicinity based on determining of induced internal electromagnetic field and 
SAR values. The anatomical shape of human jaw, which includes teeth model, and its characteristics are of great importance for absorbed electromagnetic energy measurement. The same is for the operating frequency and the distance between the electromagnetic source and the exposed object (dental amalgam). This study includes numerical calculation of the electrical field and SAR values at the frequencies of $900 \mathrm{MHz}$ and $2600 \mathrm{MHz}$ corresponding to $3 \mathrm{G}$ and $4 \mathrm{G}$ mobile networks, respectively.

\section{NuMERICAL Method, ModELling, AND Simulation}

\section{A. Model}

In order to determine the electric field distribution and values of SAR in the vicinity of dental amalgam exposed to the radiation from mobile phone, a 3D model of a human head and the model of a jaw have been developed. The model of a human jaw has been created with features, which are the closest possible to the actual human jaw. The process of modelling has been performed in few stages. First, the artificial jaw with teeth has been created by dental prosthetics (Fig. 1(a)). Further, based on dimensions and shape of that artificial model, the external looks of jaw model, which replicates the artificial model, has been designed (Fig. 1(b)). In addition, in order to perform the most accurate numerical analysis of electric field distribution and values of SAR, the model of a human jaw has been positioned inside the model of a human head. The human head model has been realized, including the morphological and anatomical characteristics corresponding to an average adult person (Fig. 2) [18]-[20]. The complete model used for simulation of electromagnetic wave propagation consists of human head with certain tissues and organs and model of human jaw. Note that layers were ideally superimposed, so that it is possible to consider the boundary conditions at the separation area between two tissues during the propagation of EM (Electromagnetic) waves from one tissue to another.

The human head model with related mobile phone position, position of the jaw, vertical cross section of the head and head tissue structure observed from above are presented at Figs 2(a). 2(b), 2(c) and 2(d) respectively. Numerical designations of tissues and organs from Fig. 2 correspond to those ones shown in Table I.

In order to understand the impact of electromagnetic radiation on the body, the detailed knowledge of the electromagnetic properties (permittivity, conductivity, and permeability) of tissues and organs is necessary. The propagation, reflection, and attenuation effects of electromagnetic waves in the human body strongly depend on these electromagnetic properties. In Table I, the electromagnetic parameters of biological tissues and organs are given [21].

Since the main goal of this study to determine electric field distribution and values of SAR within biological tissues in the vicinity of dental amalgam exposed to EM radiation, comparative analysis of two simulations was performed. One numerical calculation of electromagnetic waves propagation was carried out for human teeth without dental amalgam and the other one - with dental amalgam.

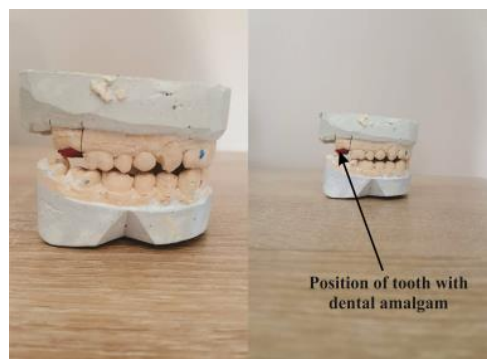

(a)

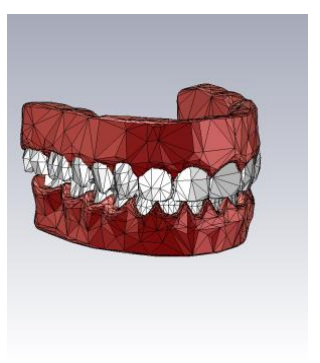

(b)
Fig. 1. External appearance of the jaw: (a) artificial human jaw created by dentist prosthetics and (b) jaw model created for simulation.

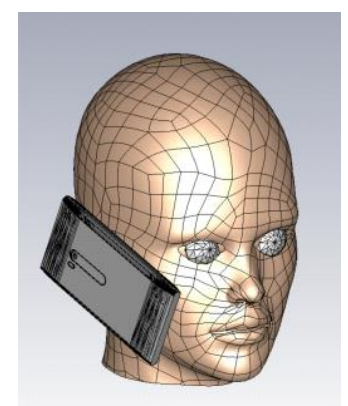

(a)

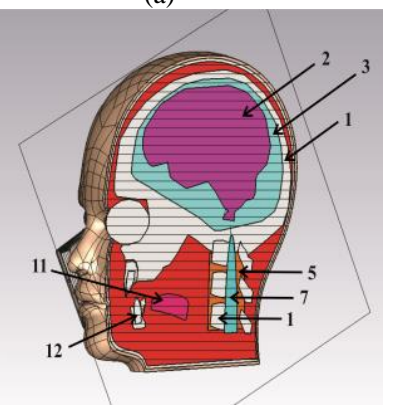

(c)

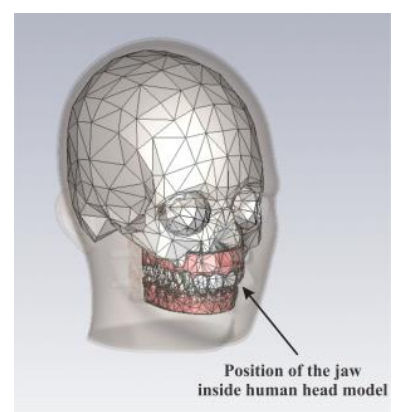

(b)

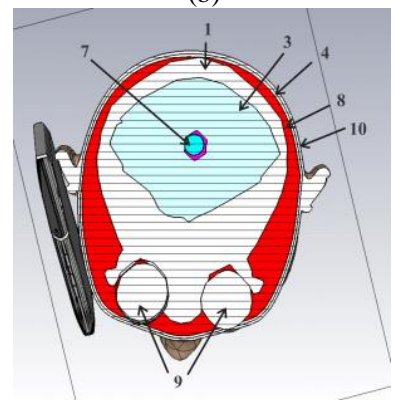

(d)
Fig. 2. External appearance and construction of the human head model with (a) related mobile phone position; (b) position of the jaw; (c) vertical cross section of the head, and (d) head tissue structure.

The dental amalgam was modelled with the following dimensions: $3 \mathrm{~mm}$ length, $2 \mathrm{~mm}$ depth, and $5 \mathrm{~mm}$ width [22]. The model of dental amalgam was modelled as a conventional dental amalgam alloy, which contains $65 \%$ silver, $25 \%$ tin, $5 \%$ copper, $2 \%$ zinc, and $3 \%$ mercury [23]. The electromagnetic characteristics of these materials are taken from material library of software package (see Table II).

As a source of electromagnetic radiation, the mobile phone model with characteristics corresponding to an actual smart phone has been developed (Fig. 3). The mobile phone model contains the following parts: the display, mobile housing, and planar inverted F antenna (PIFA). Some of the latest smart phones have PIFA antenna positioned in the microphone area or in the mouth region of the user; the latter kind of mobile phone was used in this investigation. The planar inverted $\mathrm{F}$ antenna (as radiation source) was modelled for the frequencies of $900 \mathrm{MHz}$ and $2600 \mathrm{MHz}$. Thereby, the output power and the impedance values are $\mathrm{P}=1 \mathrm{~W}$ [24] and $Z=50 \Omega$, respectively. The antenna position inside the cell phone is shown in Fig. 3. Generally, the PIFA construction depends on manufacturer. Some examples of PIFA performance, construction, and radiation pattern for certain frequency values are presented in [25]. 
TABLE I. ELECTROMAGNETIC PROPERTIES OF TISSUES AND ORGANS AT $f=900 \mathrm{MHz}$ AND $f=2600 \mathrm{MHz}$.

\begin{tabular}{|c|c|c|c|c|}
\hline \multicolumn{2}{|c|}{ Biological tissue } & \multirow{2}{*}{$\begin{array}{c}\begin{array}{c}3 \mathbf{G} \\
\mathbf{9 0 0} \mathbf{M H z}\end{array} \\
12.45 \\
\end{array}$} & \multirow{2}{*}{$\begin{array}{c}\begin{array}{c}\mathbf{4 G} \\
\mathbf{2 6 0 0} \mathbf{M H z}\end{array} \\
11.3 \\
\end{array}$} & \multirow{2}{*}{$\frac{\boldsymbol{\rho}\left[\mathbf{k g m}^{-\mathbf{3}}\right]}{1908}$} \\
\hline Cortical & $\varepsilon_{\mathrm{r}}$ & & & \\
\hline Bones & $\sigma\left[\mathrm{Sm}_{-1}{ }^{-1}\right]$ & 0.143 & 0.424 & \\
\hline \multirow{2}{*}{ Brain } & $\varepsilon_{\mathrm{r}}$ & 49.4 & 44.5 & \multirow{2}{*}{1046} \\
\hline & $\sigma\left[\mathrm{Sm}^{-1}\right]$ & 1.26 & 2.2 & \\
\hline \multirow{2}{*}{$\begin{array}{c}\text { Cerebrospi } \\
\text { nal Fluid }\end{array}$} & $\varepsilon_{\mathrm{r}}$ & 68.60 & 66 & \multirow{2}{*}{1007} \\
\hline & $\sigma\left[\mathrm{Sm}_{-1}{ }^{-1}\right]$ & 2.410 & 3.6 & \\
\hline \multirow{2}{*}{ Fat } & $\varepsilon_{\mathrm{r}}$ & 11.30 & 10.8 & \multirow{2}{*}{911} \\
\hline & $\sigma\left[\mathrm{Sm}^{-1}\right]$ & 0.109 & 0.28 & \\
\hline \multirow{2}{*}{ Cartilage } & $\varepsilon_{\mathrm{r}}$ & 42.70 & 38.4 & \multirow{2}{*}{1100} \\
\hline & $\sigma\left[\mathrm{Sm}^{-1}\right]$ & 0.782 & 1.87 & \\
\hline \multirow{2}{*}{$\begin{array}{c}\text { Pituitary } \\
\text { Gland }\end{array}$} & $\varepsilon_{\mathrm{r}}$ & 59.70 & 57 & \multirow{2}{*}{1053} \\
\hline & $\sigma\left[\mathrm{Sm}^{-1}\right]$ & 1.040 & 2.09 & \\
\hline \multirow{2}{*}{ Spinal Cord } & $\varepsilon_{\mathrm{r}}$ & 32.50 & 30 & \multirow{2}{*}{1075} \\
\hline & $\sigma\left[\mathrm{Sm}^{-1}\right]$ & 0.574 & 1.15 & \\
\hline \multirow{2}{*}{ Muscle } & $\varepsilon_{\mathrm{r}}$ & 55.00 & 52.5 & \multirow{2}{*}{1090} \\
\hline & $\sigma\left[\mathrm{Sm}^{-1}\right]$ & 0.943 & 1.84 & \\
\hline \multirow{2}{*}{ Eyes } & $\varepsilon_{\mathrm{r}}$ & 49.60 & 47.3 & \multirow{2}{*}{1052} \\
\hline & $\sigma\left[\mathrm{Sm}^{-1}\right]$ & 0.994 & 1.85 & \\
\hline \multirow{2}{*}{ Skin } & $\varepsilon_{\mathrm{r}}$ & 41.40 & 37.8 & \multirow{2}{*}{1109} \\
\hline & $\sigma\left[\mathrm{Sm}_{-1}{ }^{-}\right]$ & 0.867 & 1.54 & \\
\hline \multirow{2}{*}{ Tongue } & $\varepsilon_{\mathrm{r}}$ & 55.30 & 52.4 & \multirow{2}{*}{1090} \\
\hline & $\sigma\left[\mathrm{Sm}^{-1}\right]$ & 0.936 & 1.92 & \\
\hline \multirow{2}{*}{ Teeth } & $\varepsilon_{\mathrm{r}}$ & 12.50 & 11.3 & \multirow{2}{*}{2180} \\
\hline & $\sigma\left[\mathrm{Sm}^{-1}\right]$ & 0.143 & 0.424 & \\
\hline
\end{tabular}

TABLE II. ELECTROMAGNETIC PROPERTIES OF DENTAL AMALGAM MATERIALS.

\begin{tabular}{|c|c|c|}
\hline Materials & $\boldsymbol{\sigma}\left(\mathbf{S m}^{-\mathbf{1}}\right)$ & $\boldsymbol{\rho}\left(\mathbf{k g m}^{-\mathbf{3}}\right)$ \\
\hline Silver & $6.3 \times 10^{7}$ & 10490 \\
\hline Tin & $8.7 \times 10^{6}$ & 7287 \\
\hline Copper & $5.96 \times 10^{7}$ & 8960 \\
\hline Zinc & $1.69 \times 10^{6}$ & 7130 \\
\hline Mercury & $1.04 \times 10^{6}$ & 13550 \\
\hline
\end{tabular}

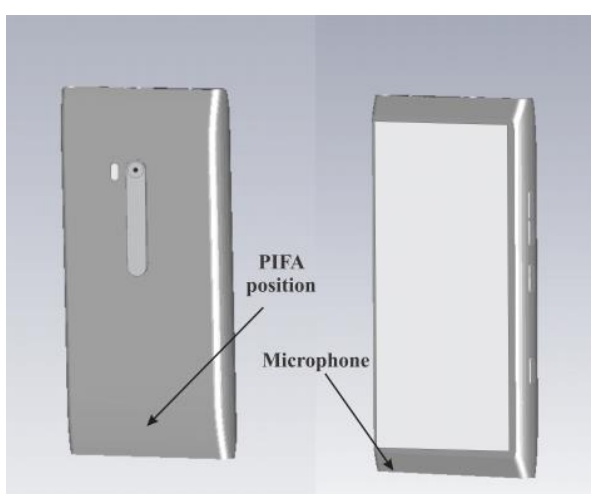

Fig. 3. External look of smart phone and position of PIFA.

For realization of precise numerical model, which correctly includes morphological and electromagnetic properties of biological tissues and organs providing calculation of the electromagnetic field distribution within the body model, the CST software package is applied [26]. CST software is based on well-known Finite Integration Technique (FIT) [27].

\section{B. SAR Calculation}

The SAR provides a direct means for measuring the RF (Radio Frequency) exposure characteristics of electromagnetic radiation source in order to ensure that source features are within the safety guidelines prescribed by safety standards and recommendations.

During the propagation of the electromagnetic wave through the human tissue, the electromagnetic energy is absorbed. The interaction between tissues and electromagnetic waves is quantitatively modelled with SAR. Actually, SAR is defined as the speed of power dissipation normalized by material density, and it can be described by expression [28]

$$
\operatorname{SAR}=\frac{\sigma}{\rho}|E|^{2}
$$

where $\sigma$ and $\rho$ are the electrical conductivity $\left(\mathrm{Sm}^{-1}\right)$ and the density of tissue $\left(\mathrm{kgm}^{-3}\right)$, respectively. It is necessary to emphasize that the electric field E (V/m) is the RMS (Root Mean Square) value.

In addition, the averaged $\mathrm{SAR}\left(\mathrm{SAR}_{\mathrm{av}}\right)$ is defined as the ratio of the power absorbed in the tissue and the tissue mass. It is obtained as

$$
\mathrm{SAR}_{\mathrm{av}}=\frac{1}{V} \int_{V} \mathrm{SAR} d V=\int_{V} \frac{1}{V} \frac{\sigma}{\rho}|E|^{2} d V .
$$

Mass-averaged SAR is usually determined for $1 \mathrm{~g}\left(\mathrm{SAR}_{1 \mathrm{~g}}\right)$ and $10 \mathrm{~g}\left(\mathrm{SAR}_{10 \mathrm{~g}}\right)$ samples. In this study, SAR is averaged only for $1 \mathrm{~g}$ due to the small teeth volumes.

\section{RESULTS}

In this section, the distribution of the electric field and SAR values are shown for different cross-sections of the human head model. Comparative analysis of the obtained results for models with and without dental amalgam is performed. The positions of cross-sections A, B, and C used for the analysis of the EM radiation impact can be seen in Fig. 4. It should be noted that the cross-sections are in planes, in which the tooth with dental amalgam is positioned. Accordingly, this investigation is focused on the electric field distribution and amount of absorbed energy near the dental amalgam (silver fillings).

\section{A. Electric Field Distribution}

This part of the paper refers to a comparative analysis of the electric field distribution within the models exposed to EM radiation at the mentioned frequencies, with and without dental amalgam. The electric field strength for the crosssections $\mathrm{A}, \mathrm{B}$, and $\mathrm{C}$ located at the mouth region is shown in Figs. 5-7, respectively. In order to make results comparable, the model with dental amalgam (right side) and model without dental amalgam (left side) are represented at the same figure. In addition, the electric field maximum value in the colour palette on the right side of the figures is set to be the same for both models in order to enable the easier comparison of the electric field distribution inside the model.

It should be mentioned that the electric field allowable values are $41 \mathrm{~V} / \mathrm{m}$ for frequency of $900 \mathrm{MHz}$ and $24.4 \mathrm{~V} / \mathrm{m}$ for frequency of $2600 \mathrm{MHz}$ [1]-[4]. These values prescribed by standard imply analysis of free space domain, when the human is absent.

From the previous Figures, if we compare the electric field distribution when the dental amalgam is present and without the dental amalgam, a significant increase in the 
strength of the electric field within the certain tissues can be noted. The highest increase of the electric field is observed in tissues that are closest to the dental amalgam (Figs. 5-7), and these values are represented in Table III for $3 \mathrm{G}$ and $4 \mathrm{G}$ frequencies.

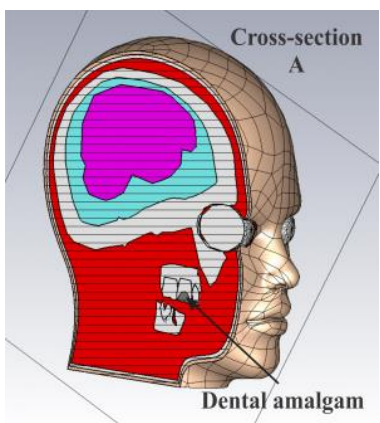

(a)

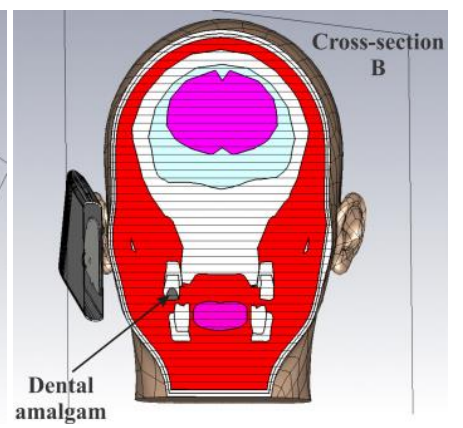

(b)

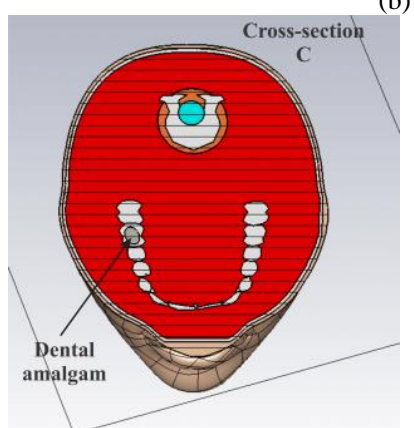

(c)

Fig. 4. (a) cross-section A; (b) cross-section B; (c) cross-section C.
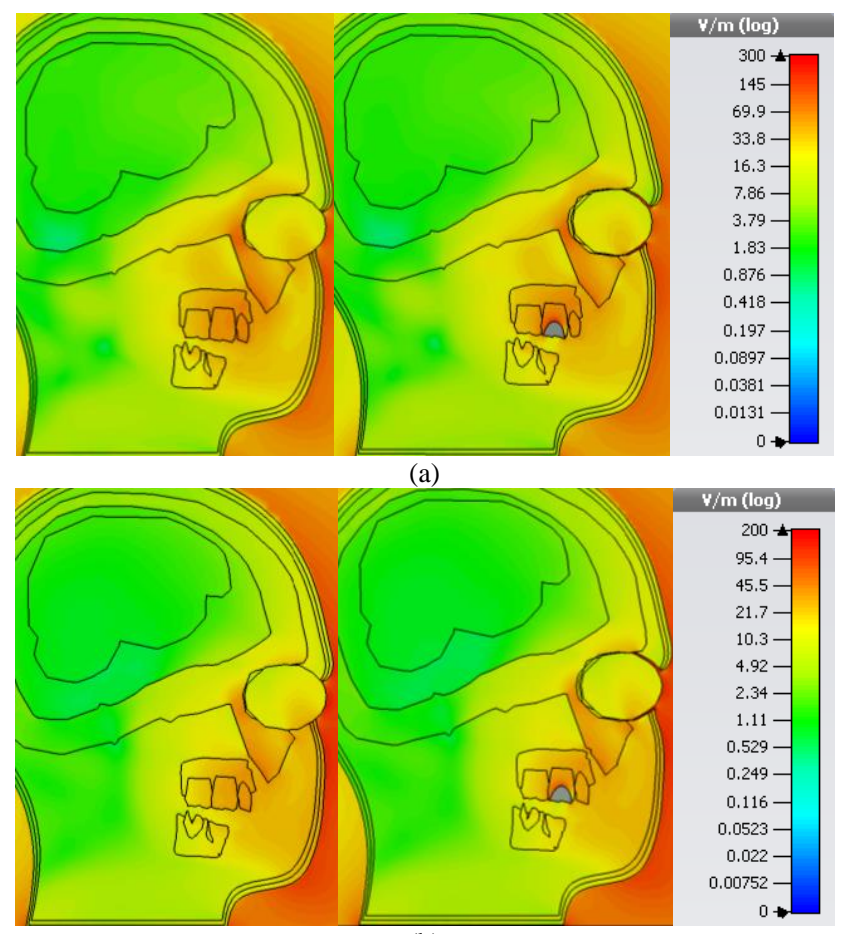

(b)

Fig. 5. Electric field distribution - cross-section A: (a) $f=900 \mathrm{MHz}$ and (b) $f=2600 \mathrm{MHz}$.

TABLE III. MAXIMUM ELECTRIC VALUES IN THE VICINITY OF DENTAL AMALGAM [V/m]

\begin{tabular}{|c|c|c|}
\hline Model & 3G-900 MHz & 4G-2600 MHz \\
\hline Without amalgam & 78.04 & 39.34 \\
\hline With amalgam & 296.11 & 136.52 \\
\hline
\end{tabular}

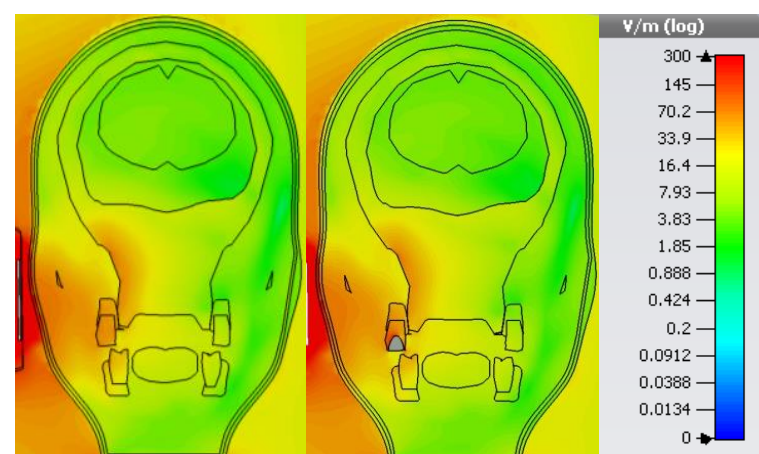

(a)

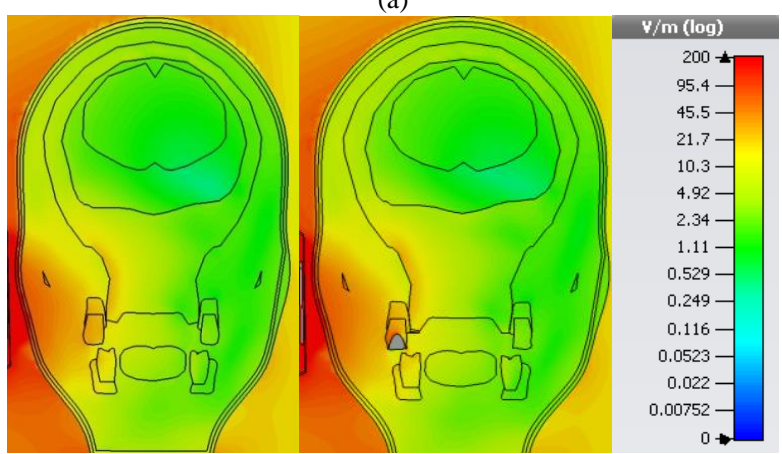

(b)

Fig. 6. Electric field distribution - cross-section B: (a) $f=900 \mathrm{MHz}$ and (b) $f=2600 \mathrm{MHz}$

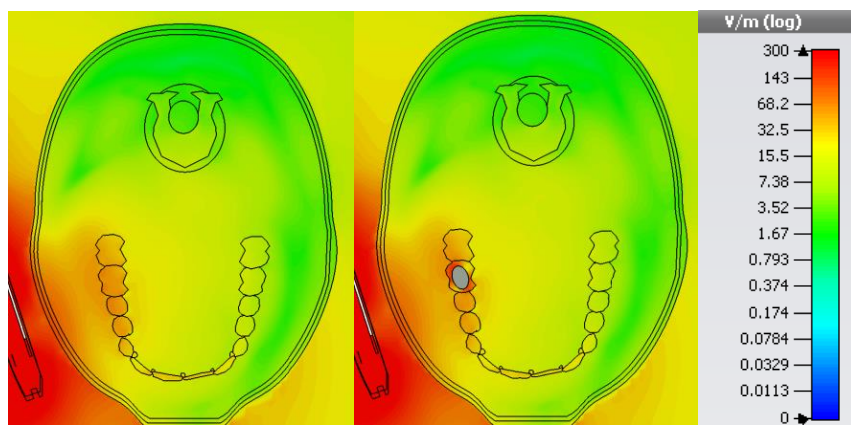

(a)

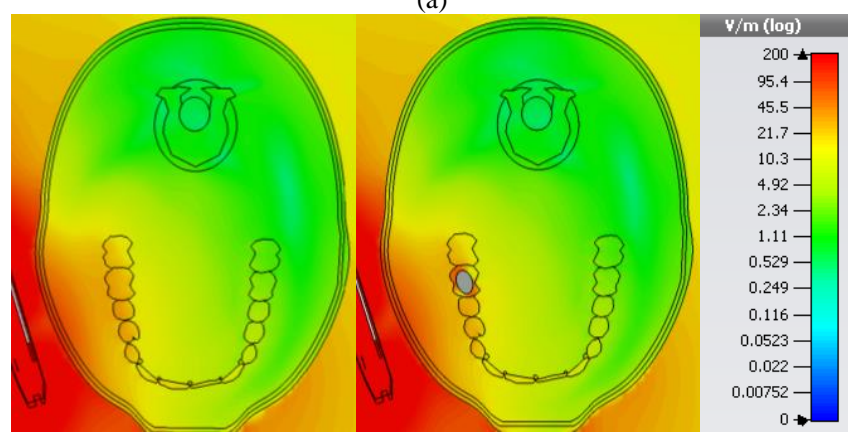

(b)

Fig. 7. Electric field distribution - cross-section C: (a) $f=900 \mathrm{MHz}$ and (b) $f=2600 \mathrm{MHz}$

The higher electric field values are observed at the frequency of $900 \mathrm{MHz}$, while these values at the LTE-4G mobile network at $2600 \mathrm{MHz}$ are lower. The electric field strength peak for the model without amalgam at the $3 \mathrm{G}$ frequency is $78.04 \mathrm{~V} / \mathrm{m}$ and this is almost four times lower than in case with dental amalgam $(296.11 \mathrm{~V} / \mathrm{m})$. This ratio is lower for $4 \mathrm{G}$ frequency and the electric field peak is 3.5 times higher inside the model with dental amalgam $(136.52 \mathrm{~V} / \mathrm{m})$.

The penetration depth decreases with the frequency 
increasing since the electric field absorption is higher in the surface layers of the organs and tissues. According to the Figures 5-7 above, the impact of electromagnetic radiation on dental amalgam is smaller at the $4 \mathrm{G}$ frequency, but the values at both frequencies are larger than the maximum allowed values prescribed by standards. In Fig. 8 and Fig. 9, the electric field distribution at the surface of a human tooth for the model without dental amalgam (left side) and for the model with amalgam (right side) are represented for the frequencies of $900 \mathrm{MHz}$ and $2600 \mathrm{MHz}$, respectively.

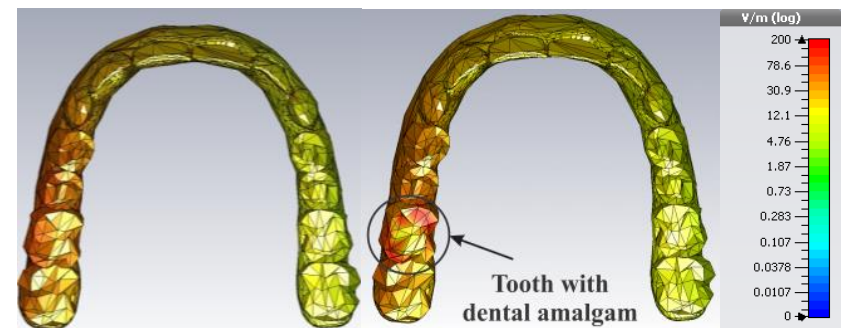

Fig. 8. Electric field distribution at the surface of model for $f=900 \mathrm{MHz}$.

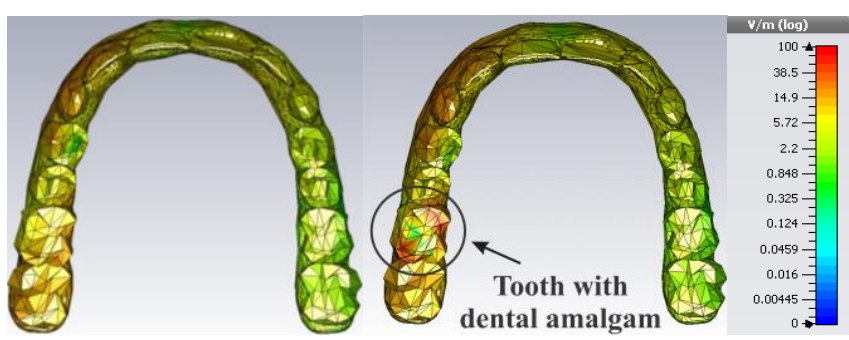

Fig. 9. Electric field distribution at the surface of model for $f=2600 \mathrm{MHz}$.

Based on the Figures 5-9, the overall conclusion is that the presence of dental amalgam (silver fillings) increases the electric field strength inside the biological tissues in its vicinity. The electric field strength is increased by four times, and therefore it cannot be neglected, because this value overcomes the allowable values mentioned above.

\section{B. SAR Calculation}

In this sub-section, a comparative analysis of the SAR values averaged for $1 \mathrm{~g}\left(\mathrm{SAR}_{1 \mathrm{~g}}\right)$ within the models (with and without dental amalgam) at the $3 \mathrm{G}$ and $4 \mathrm{G}$ mobile networks frequencies is represented. The values of $\mathrm{SAR}_{1 \mathrm{~g}}$ for the cross sections $\mathrm{A}, \mathrm{B}$, and $\mathrm{C}$ located at the mouth region are shown in Figs. 10-12, respectively. Also, as previously, on the right side of the figures, the maximum values of SAR in the colour palette are set to be the same for both models.

The SAR limit for public exposure from mobile phones in accordance with appropriate safety standards amounts 1.6 watts per kilogram $(1.6 \mathrm{~W} / \mathrm{kg})$ [2].

From the previous Figure 8 and Fig. 9, comparing the values of $\mathrm{SAR}_{1 \mathrm{~g}}$ in the cases of presence and absence of dental amalgam, a significant increase in absorbed energy amount can be noticed when the amalgam is present. The maximum increase of $\mathrm{SAR}_{1 \mathrm{~g}}$ occurs inside tissues in the vicinity of dental amalgam (Figs. 10-12), and these values are given in Table IV.

The value of the $\mathrm{SAR}_{1 \mathrm{~g}}$ at the frequency of $900 \mathrm{MHz}$ is higher than at the frequency of $2600 \mathrm{MHz}$ for the LTE-4G mobile network. The $\mathrm{SAR}_{1 \mathrm{~g}}$ peak for the model without amalgam at the $3 \mathrm{G}$ frequency is $1.41 \mathrm{~W} / \mathrm{kg}$, and this is 1.8 times lower than in case with dental amalgam $(2.6 \mathrm{~W} / \mathrm{kg})$.
This ratio in the case of $4 \mathrm{G}$ frequency is higher, and the peak of $\mathrm{SAR}_{1 \mathrm{~g}}$ is 1.9 times higher for the model with dental amalgam.

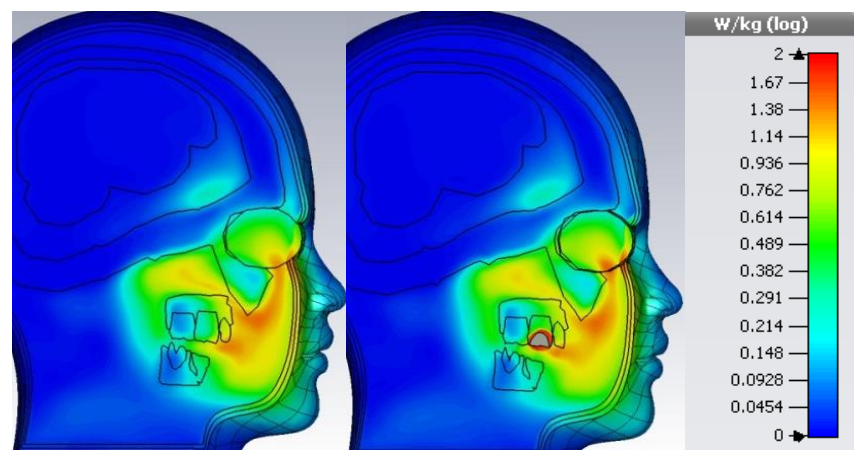

(a)

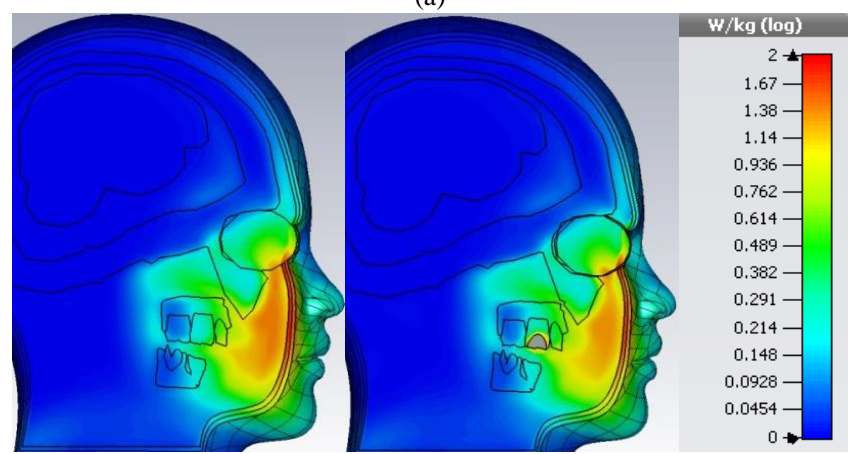

(b)

Fig. 10. Specific Absorption Rate - cross-section A: (a) $f=900 \mathrm{MHz}$ and (b) $f=2600 \mathrm{MHz}$
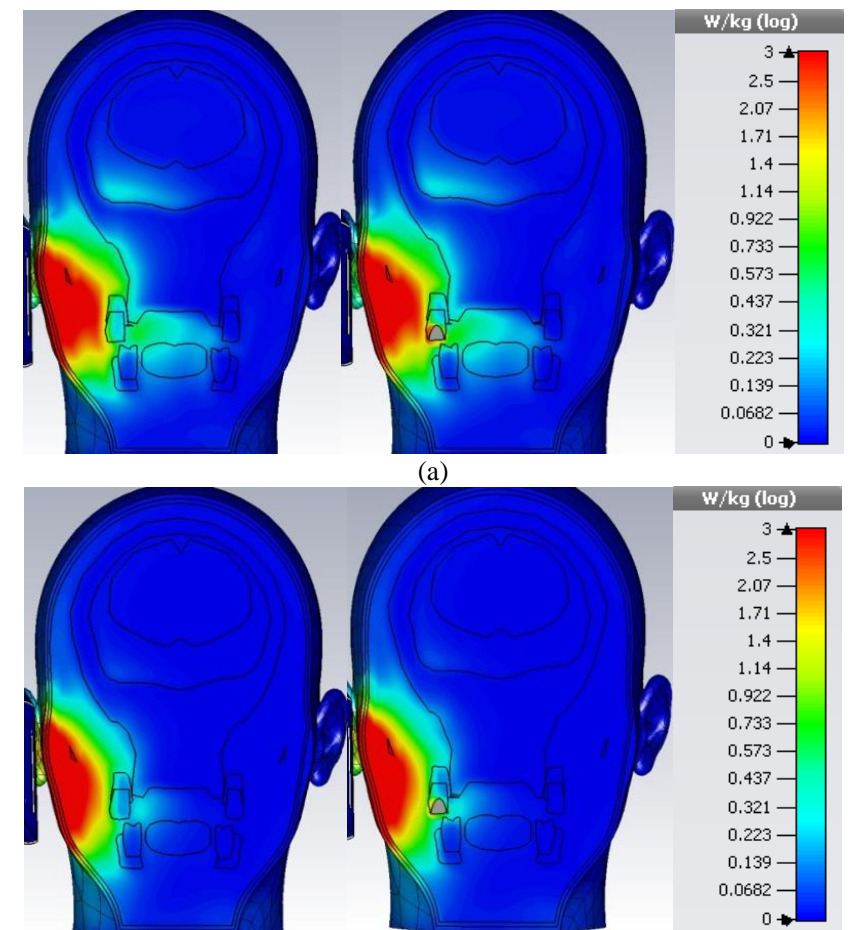

(b)

Fig. 11. Specific Absorption Rate - cross-section B: (a) $f=900 \mathrm{MHz}$ and (b) $f=2600 \mathrm{MHz}$

TABLE IV. MAXIMUM VALUE OF SAR $1 \mathrm{~g}$ [W/kg].

\begin{tabular}{|c|c|c|}
\hline Model & $\begin{array}{c}\mathbf{3 G} \\
\mathbf{9 0 0} \mathbf{~ M H z}\end{array}$ & $\begin{array}{c}\mathbf{4 G} \\
\mathbf{2 6 0 0} \mathbf{~ M H z}\end{array}$ \\
\hline Without amalgam & 1.41 & 0.91 \\
\hline With amalgam & 2.6 & 1.74 \\
\hline
\end{tabular}

According to the limit of $\mathrm{SAR}_{1 \mathrm{~g}}$, one can conclude that the 
SAR value of the model without dental amalgam is inside the safety limits for both frequencies (Table IV). When the amalgam is present, the amount of absorbed energy increases and the $\mathrm{SAR}_{1 \mathrm{~g}}$ peak overcomes the safety limits. These values amount $2.6 \mathrm{~W} / \mathrm{kg}$ for $3 \mathrm{G}$ frequencies and 1.74 $\mathrm{W} / \mathrm{kg}$ for $4 \mathrm{G}$ network, and therefore are not negligible. In addition, the $\mathrm{SAR}_{1 \mathrm{~g}}$ peak at the frequency of $900 \mathrm{MHz}$ is 1.6 times higher than the values prescribed by safety standards, while this ratio in the case of $2600 \mathrm{MHz}$ is almost 1.1 .

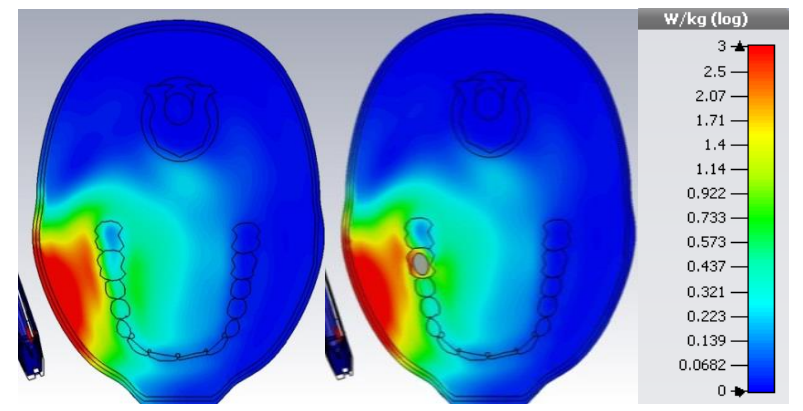

(a)

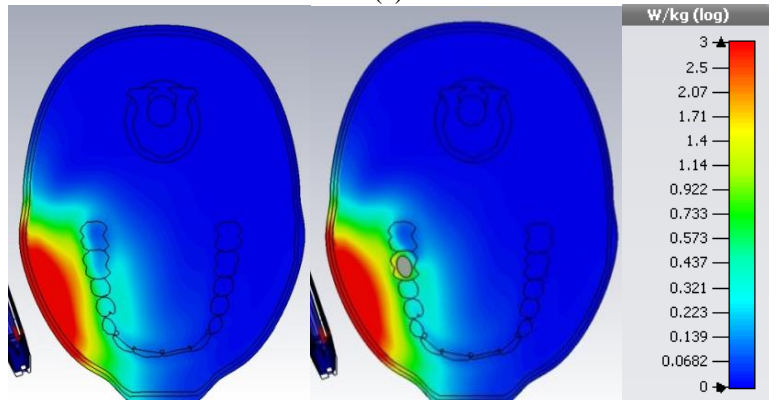

(b)

Fig. 12. Specific Absorption Rate - cross-section C: (a) $f=900 \mathrm{MHz}$ and (b) $f=2600 \mathrm{MHz}$.

It is evident from the previous Figure 10 and Fig. 11 that the increase of electromagnetic wave energy absorption exists in the vicinity of dental amalgam. Obviously, the value of $\mathrm{SAR}_{1 \mathrm{~g}}$ at the surface of tooth with dental amalgam is higher than without amalgam. This increase occurs in the case of both network frequencies ( $3 \mathrm{G}$ and $4 \mathrm{G}$ ), but the peak of $\mathrm{SAR}_{1 \mathrm{~g}}$ is higher at the frequency of $3 \mathrm{G}$ network.

\section{DISCUSSION}

According to the obtained results presented in the previous Section, it is shown that the electric field maximum value in the vicinity of dental amalgam exposed to the mobile phone radiation is higher in a presence of dental amalgam than without it. This increase of electric field is higher in the case of $3 \mathrm{G}$ mobile network. It is expected, since it is well known that the electromagnetic waves penetration depth is larger at lower frequencies. At 3G frequency, the maximum value of electric field strength in the vicinity of tooth without dental amalgam amounts $78.04 \mathrm{~V} / \mathrm{m}$, while with amalgam is $296.11 \mathrm{~V} / \mathrm{m}$, which is almost four times higher. These values at $4 \mathrm{G}$ frequency are $39.34 \mathrm{~V} / \mathrm{m}$ (without dental amalgam) and $136.52 \mathrm{~V} / \mathrm{m}$ (with dental amalgam), which is 3.5 times higher.

As it has been previously mentioned, the allowable values for the electric field are $41 \mathrm{~V} / \mathrm{m}$ and $24.4 \mathrm{~V} / \mathrm{m}$ at the frequencies of $900 \mathrm{MHz}$ and $2600 \mathrm{MHz}$, respectively. Comparing the results obtained by numerical calculation with the allowable values prescribed by adequate standards, it is evident that obtained results exceed the safety limits. The values of electric field strength in the vicinity of tooth without dental amalgam at $3 \mathrm{G}$ and $4 \mathrm{G}$ frequencies are 1.9 and 1.6 times higher than the allowable values, respectively, while this ratio is higher in the case of dental amalgam presence. The maximum values of electric field in the vicinity of dental amalgam at $3 \mathrm{G}$ and $4 \mathrm{G}$ frequencies are 7.2 and 5.6 times higher than the allowable values, respectively. It has been already emphasised the use of these values include presumption that human is absent, i.e., that observed domain is actually free space.

Based on the obtained results for SAR in the vicinity of dental amalgam, one can notice significant increasing of the absorbed energy amount when the dental amalgam is present. The maximum increase of $\mathrm{SAR}_{1 \mathrm{~g}}$ occurs inside tissues in the vicinity of dental amalgam. The higher value of the $\mathrm{SAR}_{1 \mathrm{~g}}$ in the vicinity of tooth with amalgam is observed at the frequency of $900 \mathrm{MHz}$, while the lower value is observed for the LTE-4G mobile network. The $\mathrm{SAR}_{1 \mathrm{~g}}$ peak in the vicinity of the tooth without dental amalgam at $3 \mathrm{G}$ frequency is $1.41 \mathrm{~W} / \mathrm{kg}$, while this value in the case of tooth with silver filling is $2.6 \mathrm{~W} / \mathrm{kg}$, and this is 1.8 times higher. Based on the results for amount of absorbed energy at $4 \mathrm{G}$ and $3 \mathrm{G}$ frequencies, it can be concluded that the value of $\mathrm{SAR}$ is lower in the case of $4 \mathrm{G}$ mobile networks. The $\mathrm{SAR}_{1 \mathrm{~g}}$ peak in the vicinity of the tooth without dental amalgam at $4 \mathrm{G}$ frequency is $0.91 \mathrm{~W} / \mathrm{kg}$, while this value in the case of tooth with silver filling is $1.74 \mathrm{~W} / \mathrm{kg}$, and this is 1.9 times higher.

It is necessary to recall the fact stated above that the SAR limit for public exposure from mobile phones in accordance with appropriate safety standards amounts $1.6 \mathrm{~W} / \mathrm{kg}$. If we performed comparative analysis of the results obtained by numerical calculation and the allowable values prescribed by adequate standards, we can notice that the obtained results exceed the safety limits only when the amalgam is present. The $\mathrm{SAR}_{1 \mathrm{~g}}$ in the vicinity of tooth without dental amalgam at $3 \mathrm{G}$ and $4 \mathrm{G}$ frequencies is lower than the allowable values. This cannot be said for the $\mathrm{SAR}_{1 \mathrm{~g}}$ in the vicinity of tooth with the dental amalgam. The $\mathrm{SAR}_{1 \mathrm{~g}}$ in the vicinity of dental amalgam at $3 \mathrm{G}$ and $4 \mathrm{G}$ frequencies is 1.6 and 1.1 times higher than the allowable values, respectively.

\section{CONClusions}

This study investigated the electrical field and SAR values distributions within biological tissues in the vicinity of dental amalgam exposed to the electromagnetic radiation. The numerical calculation was performed for the frequencies of $3 \mathrm{G}(900 \mathrm{MHz})$ and $4 \mathrm{G}(2600 \mathrm{MHz})$ mobile networks. The comparative analysis is presented for two models, one with and the other without dental amalgam.

The presented results suggest a conclusion that maximum electric field value in the space exposed to the mobile phone radiation exceeds allowable value with and without presence of dental amalgam. The obtained maximal values are higher for the case when dental amalgam is used. In addition, maximal field values for $3 \mathrm{G}$ frequency are higher than those ones obtained for $4 \mathrm{G}$ frequency. 
The Specific Absorption Rate values do not exceed allowable values in the observed domain, without dental amalgam presented. In the presence of dental amalgam, those values are higher than allowable ones, especially for the values corresponding to $3 \mathrm{G}$ frequency.

The presented modelling and simulation procedures have been prepared and implemented in a way that justifies confidence in the results obtained. Possible experimental validation is conditioned and limited by both practical requirements and ethical standards.

This research can be a good foundation for multidisciplinary studies involving medical professionals. It is the proper way of studying the biological effects due to the influence of dental amalgam presence in the tooth exposed to the electromagnetic radiation from mobile phone.

\section{CONFLICTS OF INTEREST}

The authors declare that they have no conflicts of interest.

\section{REFERENCES}

[1] Council recommendation of 12 July 1999 on the limitation of exposure of the general public to electromagnetic fields $(0 \mathrm{~Hz}$ to 300 $\mathrm{GHz}$ ), Official Journal of the European Communities L 199/59, 1999. [Online]. Available: https://op.europa.eu/en/publication-detail//publication/9509b04f-1df0-4221-bfa2-c7af77975556/language-en

[2] "C95.1-2005 - IEEE standard for safety levels with respect to human exposure to radio frequency electromagnetic fields, $3 \mathrm{kHz}$ to 300 GHz", in IEEE Std C95.1-2005 (Revision of IEEE Std C95.1-1991), pp. 1-238, 19 April 2006. DOI: 10.1109/IEEESTD.2006.99501.

[3] Regulations on limits of exposure to non-ionizing radiation, Official Gazette of RS, no. 104/09, 2009. [Online]. Available: http://www.kvalitet.co.rs/dokumenta/zakoni/nejonizujuce/Pravilniko-granicama-izlaganja-nejonizujucim-zracenjima.pdf (in Serbian)

[4] ICNIRP statement on the "guidelines for limiting exposure to timevarying electric, magnetic, and electromagnetic fields (up to 300 $\mathrm{GHz})$ ", International Commission on Non-Ionizing Radiation Protection, 2009. [Online]. Available: https://www.icnirp.org/cms/upload/publications/ICNIRPemf gdl.pdf

[5] IARC classifies radiofrequency electromagnetic fields as possibly carcinogenic to humans, International Agency for Research on Cancer, Press Release no. 208, 2011. Available: https://www.iarc.fr/wp-content/uploads/2018/07/pr208_E.pdf

[6] A. Lee, H. Choi, H. Lee, and J. Pack, "Human head size and SAR characteristics for handset exposure", Etri Journal, vol. 24, no. 2, pp. 176-180, 2002. DOI: 10.4218/etrij.02.0202.0202.

[7] N. K. Kouveliotis, S. C. Panagiotou, P. K. Varlamos, and C. N. Capsalis, "Theoretical approach of the interaction between human head model and a mobile handset helical antenna using numerical methods", Progress In Electromagnetics Research, vol. 65, pp. 309327, 2006. DOI: 10.2528/PIER06101901.

[8] A. Z. El Dein and A. Amr, "Specific absorption rate (SAR) induced in human heads of various sizes when using a mobile phone", in Proc. of the World Congress on Engineering, 7th International Multi-Conference on Systems Signals and Devices (SSD), Amman, Jordan, 2010, vol. 1. DOI: 10.1109/SSD.2010.5585549.

[9] R. Hirtl and G. Schmid, "Numerical analysis of specific absorption rate in the human head due to a $13.56 \mathrm{MHz}$ RFID-based intra-ocular pressure measurement system", Physics in Medicine and Biology, vol. 58, no. 18, pp. 267-277, 2013. DOI: 10.1088/0031$9155 / 58 / 18 / \mathrm{N} 267$.

[10] F. Schaumburg and F. A. Guarnieri, "Assessment of thermal effects in a model of the human head implanted with a wireless active microvalve for the treatment of glaucoma creating a filtering bleb", Physics in Medicine and Biology, vol. 62, no. 9, pp. 191-2013, 2017. DOI: 10.1088/1361-6560/aa5dae.

[11] C. Buccella, V. De Santis, and M. Feliziani, "Numerical prediction of SAR and thermal elevation in a $0.25-\mathrm{mm} 3-\mathrm{D}$ model of the human eye exposed to handheld transmitters", in Proc. of IEEE International
Symposium on Electromagnetic Compatibility, Honolulu, USA, 2007. DOI: 10.1109/ISEMC.2007.77.

[12] V. Stanković, D. Jovanović, D. Krstić, V. Marković, and N. Cvetković, "Temperature distribution and specific absorption rate inside a child's head", International Journal of Heat and Mass Transfer, vol. 104, pp. 559-565, 2017. DOI: 10.1016/j.ijheatmasstransfer.2016.08.094.

[13] V. Stanković, D. Jovanović, D. Krstić, V. Marković, and M. Dunjić, "Calculation of electromagnetic field from mobile phone induced in the pituitary gland of children head model", Military Medical and Pharmaceutical Journal of Serbia, vol. 74, no. 9, pp. 854-861, 2017. DOI: 10.2298/VSP151130279S.

[14] W. J. Rea, Y. Pan, E. J. Fenyves, I. Sujisawa, H. Suyama et al., "Electromagnetic field sensitivity", Journal of Bioelectricity, vol. 10, no. 1-2, pp. 241-256, 1991. DOI: 10.3109/15368379109031410.

[15] G. J. Rubin, J. Das Munshi, and S. Wessely, "Electromagnetic hypersensitivity: A systematic review of provocation studies", Psychosomatic Medicine, vol. 67, no. 2, pp. 224-232, 2005. DOI: 10.1097/01.psy.0000155664.13300.64

[16] G. J. Rubin, J. Das Munshi, and S. Wessely, "A systematic review of treatments for electromagnetic hypersensitivity", Psychotherapy and Psychosomatics, vol. 75, pp. 12-18, 2006. DOI: 10.1159/000089222.

[17] Y. Fujii, "Gold alloy dental inlay for preventing involuntary body movements caused by electromagnetic waves emitted by a cell phone", Open Journal of Antennas and Propagation, vol. 2, pp. 37 43, 2014. DOI: 10.4236/ojapr.2014.24005.

[18] E. Conil, A. Hadjem, F. Lacroux, M. F. Wong, and J. Wiart, "Variability analysis of SAR from $20 \mathrm{MHz}$ to $2.4 \mathrm{GHz}$ for different adult and child models using finite-difference time-domain", Physics in Medicine and Biology, vol. 53, no. 6, pp. 1511-1525, 2008. DOI: 10.1088/0031-9155/53/6/001.

[19] M. Fujimoto, A. Hirata, J. Wang, O. Fujiwara, and T. Shiozawa, "FDTD-derived correlation of maximum temperature increase and peak SAR in child and adult head models due to dipole antenna", IEEE Transactions on Electromagnetic Compatibility, vol. 48, no. 1, pp. 240-247, 2006. DOI: 10.1109/TEMC.2006.870816.

[20] V. Stanković, D. Jovanović, D. Krstić, and N. Cvetković, "Electric field distribution and SAR in human head from mobile phones", in Proc. of the 9th International Symposium on Advanced Topics in Electrical Engineering, Bucharest, Romania, 2015, pp. 392-397. DOI: 10.1109/ATEE.2015.7133835.

[21] P. A. Hasgall, F. Di Gennaro, C. Baumgartner, E. Neufeld, B. Lloyd et al., "IT'IS database for thermal and electromagnetic parameters of biological tissues", Version 4.0, May 15, 2018. DOI: 10.13099/VIP21000-04-0.

[22] M. Paknahad, S. M. Mortazavi, S. Shahidi, G. Mortazavi, and M. Haghani, "Effect of radiofrequency radiation from Wi-Fi devices on mercury release from amalgam restorations", Journal of Environmental Health Science and Engineering, vol. 14, no. 12, 2016. DOI: 10.1186/s40201-016-0253-z.

[23] E. Rodríguez-Farre, E. Testai, E. Bruzell, W. De Jong, G. Schmalz et $a l .$, "The safety of dental amalgam and alternative dental restoration materials for patients and users", Regulatory Toxicology and Pharmacology, vol. 79, pp. 108-109, 2016. DOI: 10.1016/j.yrtph.2015.12.015.

[24] "C95.3-2002 - IEEE recommended practice for measurements and computations of radio frequency electromagnetic fields with respect to human exposure to such fields, $100 \mathrm{kHz}-300 \mathrm{GHz}$ ", in IEEE Std C95.3-2002 (Revision of IEEE Std C95.3-1991), pp. i-126, 2002. DOI: 10.1109/IEEESTD.2002.94226.

[25] J. Toro and Y. K. Choukiker, "Design and analysis of meanderline PIFA antenna with MIMO system for mobile handheld device", in Proc. of International Conference on Trends in Electronics and Informatics (ICEI), Tirunelveli, India, 2017, pp. 1061-1065. DOI: 10.1109/ICOEI.2017.8300872.

[26] Dassault Systèmes, CST (Computer Simulation Technology) Studio Suite, 2009. [Online]. Available: www.cst.com

[27] T. Clemens and T. Weiland, "Discrete electromagnetism with the Finite Integration Technique", Progress in Electromagnetics Research, vol. 32, pp 65-87, 2001. DOI: 10.2528/PIER00080103.

[28] M. A. Ebrahimi-Ganjeh and A. R. Attari, "Interaction of dual band helical and PIFA handset antennas with human head and hand", Progress in Electromagnetics Research, vol. 77, pp. 225-242, 2007 DOI: 10.2528/PIER07081804. 